\title{
Erratum zu: Vorstellung und Kompetenz
}

Moritz Krell

\section{Erratum zu: Kapitel 6 in: B. Reinisch et al. (Hrsg.), Biologiedidaktische Vorstellungsforschung: Zukunftsweisende Praxis, https://doi.org/10.1007/978-3-662-61342-9_6}

Im Kapitel „Vorstellung und Kompetenz“ wurden unter „Weiterführende Literatur“ noch zwei Titel ergänzt.

Die korrigierte Version des Kapitels ist verfügbar unter https://doi.org/10.1007/978-3-662-61342-9_6

M. Krell $(\bowtie)$

Didaktik der Biologie, Freie Universität Berlin, Berlin, Deutschland

E-Mail: moritz.krell@fu-berlin.de 